\title{
Mapping Ground Cover Using Hyperspectral Remote Sensing after the 2003 Simi and Old Wildfires in Southern California
}

\author{
Sarah A. Lewis ${ }^{1, *}$, Leigh B. Lentile ${ }^{2}$, Andrew T. Hudak ${ }^{1}$, Peter R. Robichaud ${ }^{1}$, \\ Penelope Morgan ${ }^{2}$ and Michael J. Bobbitt ${ }^{2}$
}

${ }^{1}$ Forest Service, US Department of Agriculture, Rocky Mountain Research Station 1221 S. Main Street, Moscow, Idaho 83843

${ }^{2}$ University of Idaho, Department of Forest Resources

$6^{\text {th }}$ and Line Street, Moscow, Idaho 83844-1133

*Corresponding author: Tel.: (208) 883-2346; e-mail: sarahlewis@fs.fed.us

\begin{abstract}
Wildfire effects on the ground surface are indicative of the potential for post-fire watershed erosion response. Areas with remaining organic ground cover will likely experience less erosion than areas of complete ground cover combustion or exposed mineral soil. The Simi and Old fires burned $\sim 67,000$ ha in southern California in 2003. Burn severity indices calculated from pre- and postfire multispectral imagery were differenced (i.e., differenced Normalized Burn Ratio (dNBR)) to highlight fire-induced changes to soil and vegetation. Aerial and field hyperspectral data were also collected together with field ground cover measurements soon after the fires. Spectral endmembers representing green vegetation, nonphotosynthetic vegetation (NPV), charred NPV, and charred and uncharred inorganic materials (soil, ash, and rock) were used in a constrained linear spectral unmixing process to determine the post-fire fractional ground cover of each component on the ground surface. The spectral unmixing results, dNBR, and a Relative dNBR (RdNBR) were validated using field-measured fractional ground cover estimates to determine which product best predicted the conditions on the ground. The spectral unmixing results were significantly correlated to all classes of charred and uncharred organics and inorganics, and the dNBR was the best indicator of charred soil and green vegetation. The RdNBR had several significant correlations with the ground data, yet did not consistently correlate well with any specific ground cover types. A map of post-wildfire ground cover and condition, especially exposed soil and remaining vegetative cover, is a good indicator of the fire's effect on the ground surface and the resulting potential for hydrologic response.
\end{abstract}

Keywords: burn severity, dNBR, erosion potential, hyperspectral data, Relative dNBR, southern California wildfires, spectral mixture analysis

Citation: Lewis, S.A., L.B. Lentile, A.T. Hudak, P.R. Robichaud, P. Morgan and M.J. Bobbitt. 2007. Mapping ground cover using hyperspectral remote sensing after the 2003 Simi and Old wildfires in southern California. Fire Ecology 3(1): 109-128. 


\section{INTRODUCTION}

Post-wildfire maps are created from remotely sensed data as soon as the fire is out to capture immediate post-fire conditions of soils and vegetation. These maps are commonly referred to as burn severity maps and are primarily used to assist rapid-response Burned Area Emergency Response (BAER) teams in assessing the immediate and longterm fire effects on vegetation, soil, and related ecological processes (Lentile et al. 2006). Standard burn severity mapping methodologies are based on classification of spectral indices (such as the Normalized Burn Ratio, or NBR) calculated from differenced pre- and postfire multispectral satellite imagery (Key and Benson 2006, Clark et al. 2003). For these post-fire maps, the landscape is classified into categories of unburned, low, moderate, and high burn severity, corresponding to the magnitude of change in the post-wildfire appearance of vegetation, litter, and soil (Miller and Yool 2002, Lentile et al. 2006, Lutes et al. 2006).

Effects of fire on the ground surface with erosion-related implications include an increase in exposed soil and ash and a decrease in protective ground cover such as litter and duff. Post-fire organic ground cover, whether charred or uncharred, can provide protection against soil erosion (Ice et al. 2004, Kokaly et al. 2007). Conversely, areas with exposed mineral soil or ash cover increase the risk for erosion by wind and water (DeBano 2000, Robichaud 2000, Ravi et al. 2006). Ash cover is indicative of complete organic material combustion. Because a water repellent soil layer may be formed when these organic materials burn on the soil surface, reduced infiltration is often found where post-fire ash cover is high (DeBano 2000, Lewis et al. 2006). In such cases, the top $1 \mathrm{~cm}$ to $5 \mathrm{~cm}$ of the soil profile above the water repellent layer may hold water, but once this layer becomes saturated, as often occurs following intense rainfall, erosion is likely, particularly on steep slopes with loose, coarse textured soils. Additionally, these fireinduced water repellent soil conditions occur when waxy chemicals from plant materials are volatilized during burning and coat coarse textured soil particles at or near the soil surface, which is common in chaparral communities (Barro and Conard 1991, CDF 2003, Hubbert et al. 2006).

The chaparral community is a shrubby, sclerophyllous vegetation type that is common in middle elevations throughout much of California (Barro and Conard 1991). Common chaparral tree and shrub genera include Adenostoma, Arctostaphylos, Ceanothus, Cercocarpus, Prunus, Quercus, and Rhamnus. Chaparral vegetation is well adapted to frequent fires that were historically common in the area. Chaparral plant adaptations include rapid post-fire root sprouting, prolific seeding, seed banking, fire-stimulated seed germination, and allelopathy (Hanes 1977, Keeley 2006). Frequent fire results in conversion of shrubdominated systems to those dominated by a mix of non-native annual grasses and forbs from the Mediterranean Basin.

The 2003 southern California wildfires burned $\sim 300,000$ ha, much of which was in chaparral vegetation that has a more open canopy and less litter accumulation on the ground as compared to a typical coniferous forest. These conditions are due in part to the rocky soils in the area and relatively low rainfall that prevent vegetation from becoming dense, except in segregated patches. These vegetation patterns create a unique situation when classifying the severity of the fire using a differenced index such as dNBR (differenced normalized burn ratio) that is dependent on the magnitude of change from pre- to post-fire condition (Miller and Thode 2007). Where vegetation is sparse, the complete removal of vegetation due to fire will be classified as high burn severity, even though the relative change to the pre-fire condition and the soil effects on the soil are less severe than similarly classified burned non-chaparral systems. This potentially 
leads to unnecessary erosion mitigation efforts based on the calculated change in reflectance, rather than the physical alteration of the soil. Miller and Thode (2007) have recently proposed a new index, the Relative dNBR (RdNBR) that takes into account the relative pre-fire to postfire change in amount of vegetation across the landscape. They suggest that this relative index may be more appropriate than the $\mathrm{dNBR}$ for mapping sparse vegetation or mixed vegetation types.

Higher spatial and spectral resolution airborne hyperspectral data have the potential to improve traditional post-fire maps by providing fine-scale quantitative information about postfire ground cover and conditions (Robichaud et al. 2007). Rather than applying a discrete classification to an area, a final product from hyperspectral imagery can provide an estimate of the percent residual post-fire charred ground cover and ash for an area (pixel) as small as $4 \mathrm{~m}$ to $5 \mathrm{~m}$. This information may help to identify locations where post-fire rehabilitation treatments are necessary by better quantifying the effects of the fire on the ground surface.

The reflectance from a specific image pixel is a mixture of the individual reflectance spectra (endmembers) of surface materials (Adams et al. 1985, Smith et al. 1990, Roberts et al. 1993). Each pixel retains the characteristic features of the individual spectra from each of the component reflective materials. Once endmember spectra are identified, spectral unmixing of individual pixels can estimate the fractional component spectra and, in turn, the physical fractional component of the materials within the pixels (Adams et al. 1985, Roberts et al. 1993, Theseira et al. 2003). Most rural landscapes can be mapped as endmember combinations of green vegetation, nonphotosynthetic vegetation, soil and rock, and shade (Roberts et al. 1993, Adams et al. 1995, Theseira et al. 2003). More specifically related to fire, hyperspectral imagery has been used to map fractional cover of ash, soil, green and non-photosynthetic vegetation in post-fire areas
(Jia et al. 2006, Kokaly et al. 2007, Robichaud et al. 2007). Our objectives were to assess the potential of hyperspectral imagery to provide a better estimate of post-fire soil condition, particularly the amount of exposed mineral soil, than had been achieved with traditional multispectral imagery.

\section{METHODS}

\section{Study Area}

The Simi and Old fires were two of several large wildfires that burned throughout southern California during the fall of 2003 (Figure 1). These fires threatened thousands of homes and impacted air and water quality throughout the region. The Simi fire began on 25 October 2003 and burned 43,800 ha in Ventura and Los Angeles counties before being contained on 2 November 2003 (Clark et al. 2003). Driven by strong Santa Ana winds, the fire jumped State Highway 126 and burned around the densely populated towns of Simi Valley, Moorpark, and Saticoy, California. The Simi fire burned in a mix of vegetation types including chaparral (the dominant vegetation type), coastal sage scrub, and annual grasslands across a diversity of topographic conditions including sandy, rolling hills and very steep, rocky terrain. The underlying bedrock in the area is comprised of sedimentary rock with overlying sandy loam soils (USDA, 2006). The soils and rock are light colored and large patches of rocky outcrops are common.

Immediatelypost-fire, aburnseveritymap for the Simi fire was created from post-fire airborne multispectral MASTER imagery (masterweb. jpl.nasa.gov) acquired on 1 November 2003 (Clark et al. 2003). The majority of the area within the Simi fire perimeter was burned at low or moderate severity, and BAER (Burned Area Emergency Response) teams in the field reported that the burn severity map was generally representative of the conditions observed on the ground (CDF 2003, Clark et 


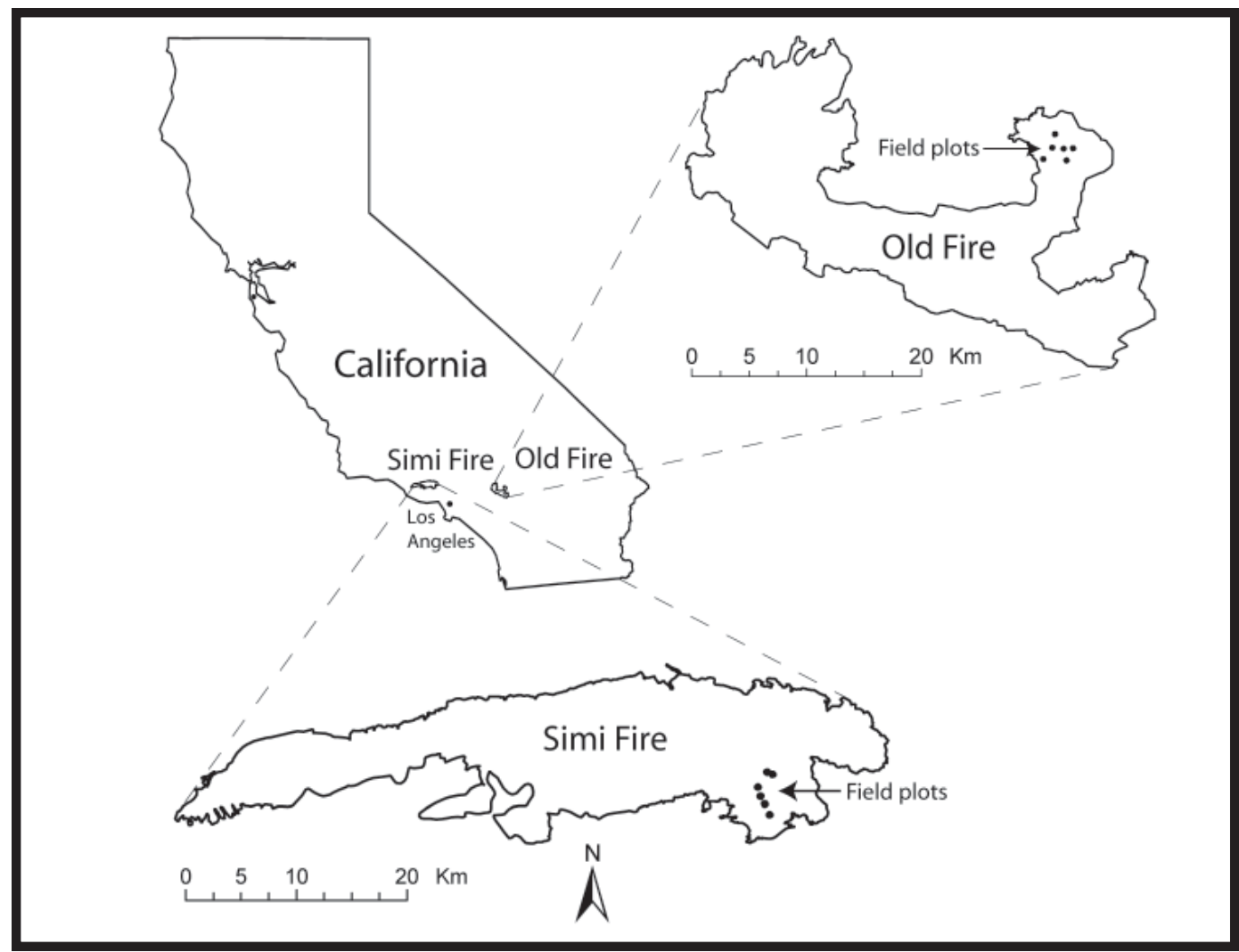

Figure 1. Map of the state of California, showing the locations of the Simi and Old fires. The field plot locations are shown within each fire.

al. 2003). However, several watersheds were assessed at a higher severity than indicated on the map and were at risk for increased post-fire erosion and debris flow (Cannon et al. 2003, CDF 2003). The BAER assessment team also noted the presence of white ash in severely burned areas, which indicated a high likelihood of water repellent soils and increased erosion potential (CDF 2003, Lewis et al. 2007).

The Old fire began on 28 October 2003 and burned 23,300 ha north of San Bernardino, California. The Old fire burned in chaparral at lower elevations and interior woodland vegetation at higher elevations, both on steep, rocky terrain. The Old fire burned more in the wildland urban interface than did the Simi fire. The area around Lake Arrowhead is densely populated with homes deep in the wooded areas, much of which had sustained damage from a serious mountain pine beetle outbreak (Savage 1997, McCullough et al. 1998). The combined effects of frequent human and natural ignitions, hot dry summers, frequent and extended droughts, high flammability of chaparral vegetation, and forest trees killed by bark beetles, made these ecosystems extremely susceptible to intense crown fires (Barro and Conard 1991, Keeley 2000, Keeley and Fotheringham 2001). The immediate post-fire burn severity map for the Old fire was created from MODIS imagery that was acquired on 5 November 2003 (Clark et al. 2003). Like for the Simi fire, these maps were used in the BAER team's assessment of the potential for increased runoff and erosion and to guide post-fire rehabilitation activities. Based on the BAER team findings that $50 \%$ of the chaparral areas and $30 \%$ of the conifer forest areas that burned at moderate or high burn severity had water repellent soils, aerial straw mulch was prescribed to mitigate erosion on slopes above areas with values at risk, such as houses, roads, and water supplies (Hubbert 2005). 


\section{Field Data Collection}

Post-fire soil and vegetation data were collected in December 2003 at six sites on each fire. These sites were selected using the immediate post-fire burn severity maps as a guide and classified by observation in the field as low, moderate, or high severity if tree or shrub crowns were predominantly green, brown, or black, respectively. On the Simi fire, two study sites were classified as low burn severity, three as moderate and one as high. On the Old fire, one site was classified as low burn severity, three as moderate and two as high. These burn severity classes were only used as a general guide to ensure that the field data covered the full range of burn severity conditions within each fire. Each site was centered in a random location $80 \mathrm{~m}$ to $140 \mathrm{~m}$ from the nearest access road, within a consistent stand and burn severity condition. Each site consisted of nine $8 \mathrm{~m} \mathrm{x} 8$ $\mathrm{m}$ plots and each plot was comprised of fifteen $1 \mathrm{~m} \times 1 \mathrm{~m}$ subplots, for a total of 135 subplots. Plot centers were geolocated with a global positioning system (GPS) and differentially corrected. Subplot centers were positioned with measurement tape and compass based on systematic distances and bearings from plot center (see detailed description in Hudak et al. 2007).

At the subplot scale, the fractional cover of green vegetation, rock, mineral soil, ash, litter (new and old), and any large organic matter (logs, branches or stumps) were ocularly estimated. The percent char, if any, of each ground cover component was also recorded. Minor ground cover fractions were estimated first, and a value of one percent was recorded if there was a trace of the component within the subplot. The more abundant fractional ground cover components (often exposed mineral soil and rock, ash, and litter) were then estimated in 5\% increments with the largest cover component estimated last. All cover fractions were required to sum to unity. Exposed mineral soil and rock were considered ground cover for the purpose of accounting for all physical space within a plot. New litter, mostly fallen leaves and needles deposited post-fire from scorched shrubs and trees, was estimated separately from the other cover fractions present at the time of the burn, to better deduce the ground conditions immediately after the fire. Thus, new litter was not included in the cover fractions that summed to unity. At the center of each site, the depth of new litter, old litter, and duff were measured; the canopy cover was estimated using a convex spherical densiometer; and a digital photo was taken for reference.

\section{Remotely Sensed Data Collection}

Field spectra. Multiple spectra of soil, rock, and green, non-photosynthetic vegetation (NPV), and charred NPV materials were collected in December 2003 after both the Simi and Old fires using an ASD Pro-FR field spectroradiometer(Analytical Spectral Devices, Boulder, Colorado, USA). Spectra were collected with the bare tip foreoptic (FOV 22 $\left.2^{\circ}\right)$ pointed at the target material. The ASD Pro-FR sampling interval is $1.4 \mathrm{~nm}$ over the $350 \mathrm{~nm}$ to $1,050 \mathrm{~nm}$ wavelength range and $2 \mathrm{~nm}$ over the $1,000 \mathrm{~nm}$ to $2,500 \mathrm{~nm}$ range, spanning nearly the same portion of the electromagnetic (EM) spectrum as the Probe I sensor used for airborne imaging. These measurements are interpolated at every $1 \mathrm{~nm}$ wavelength and reported in 2,151 contiguous channels. The field spectrometer was calibrated against a Spectralon (Labsphere, North Sutton, New Hampshire, USA) 100\% reflective panel immediately before and at frequent intervals during field spectra collection to account for changing light and atmospheric conditions. Spectralon is a bright calibration target with well-documented reflectance in the $400 \mathrm{~nm}$ to $2,500 \mathrm{~nm}$ region of the EM spectrum. Absolute reflectance was calculated at the time of data collection for all spectra by dividing field reflectance by the bright target reflectance. Representative spectra from the Old fire are shown in Figure 2. 


\section{Spectral Reflectance of Endmembers}

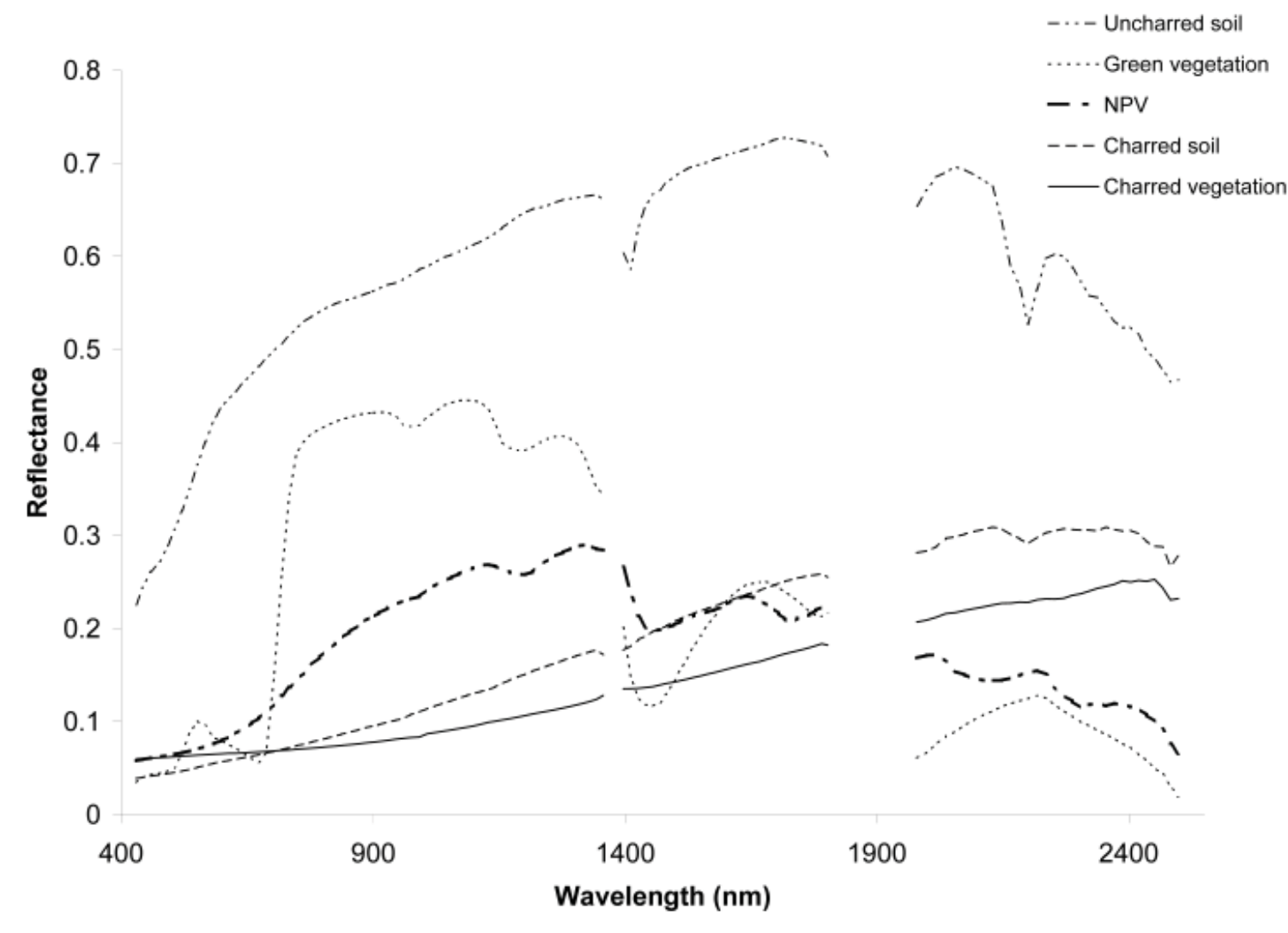

Figure 2. Example field spectra of uncharred soil, green vegetation, non-photosynthetic vegetation, charred soil, and charred vegetation (NPV) field spectra collected from the Old fire. Water absorption bands in the ranges of 1360-1400 $\mathrm{nm}$ and 1800-1980 $\mathrm{nm}$ were removed.

Airborne hyperspectral. Airborne hyperspectral imagery, which covered the range of burn severities observed and included all field sites, was collected on 4 January 2004, starting at $1123 \mathrm{~h}$ PST and concluding before $1300 \mathrm{~h}$. On this date at the collection start time, the solar zenith angel was $57.7^{\circ}$, which is a higher angle than ideal ( $45^{\circ}$ and lower is desirable). One flight line of data was collected over the Simi fire (Figure 3) and five flight lines of data were collected over the Old fire (Figure 4). The Probe I whisk-broom sensor (Earth Search Sciences Inc. (ESSI), Lakeside, Montana, USA) was flown at 2,100 $\mathrm{m}$ above ground level and data were collected along a track $\sim 28 \mathrm{~km}$ long and $2.3 \mathrm{~km}$ wide, corresponding to a 512pixel wide swath with a $4.2 \mathrm{~m}$ by $4.2 \mathrm{~m}$ Ground Instantaneous Field of View at nadir. Reflected
EM energy from the surface was received in 128 contiguous spectral bands that spanned $432 \mathrm{~nm}$ to $2,512 \mathrm{~nm}$, with a spectral bandwidth of $11 \mathrm{~nm}$ to $19 \mathrm{~nm}$.

Radiometric pre-processing. The airborne hyperspectral data were converted to reflectance using ACORN (Atmospheric CORrection Now) without any additional artifact suppression (AIG 2002). These reflectance data were further refined with a radiative transfer groundcontrolled (RTGC) calibration (Clark et al. 2002).

Geometric pre-processing. An on-board GPS and inertial measurement unit (IMU) acquired geolocation data that were matched with the spectral data. The geolocation data, 


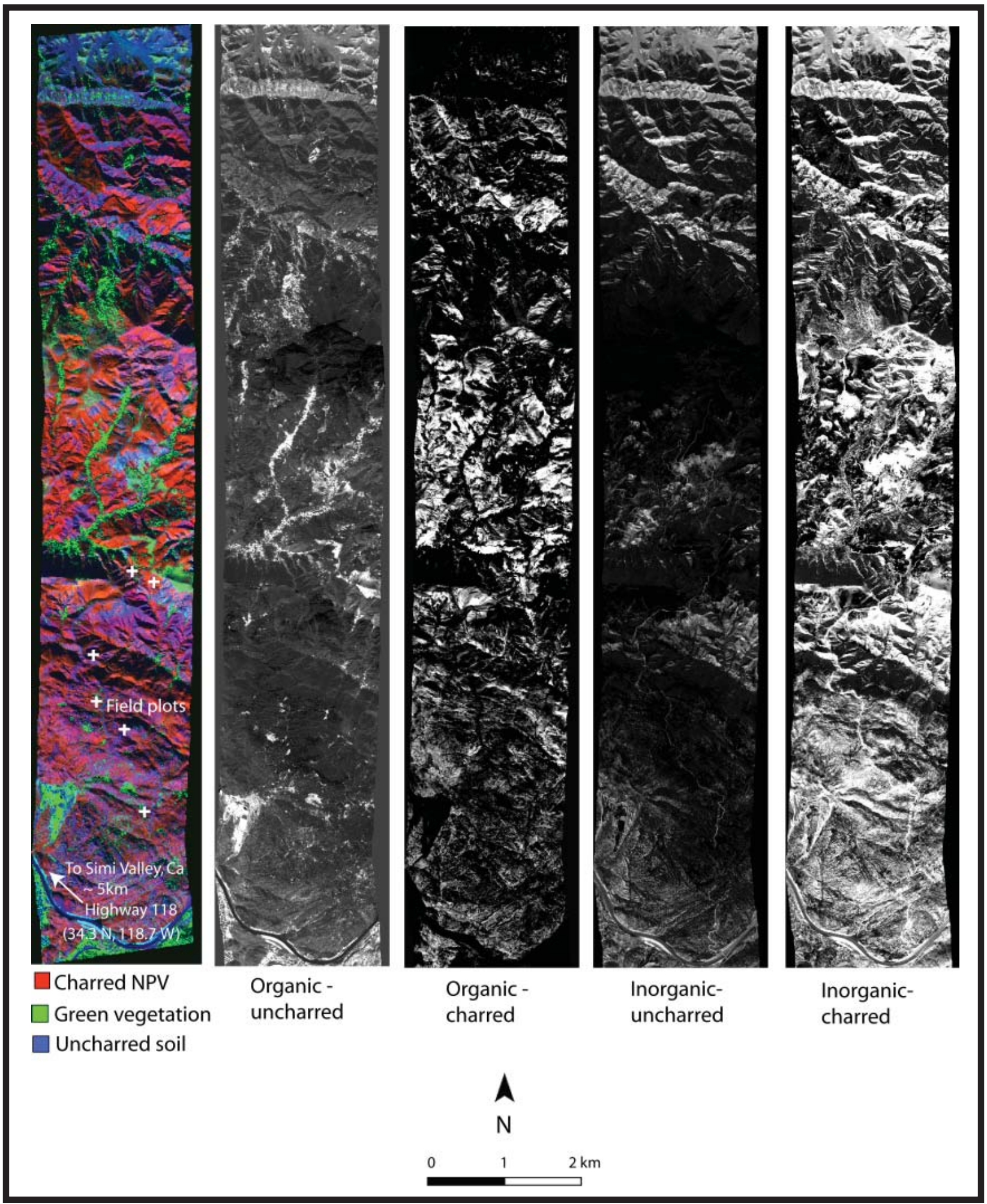

Figure 3. Hyperspectral images of the Simi fire highlighting the spectral unmixing results of each major ground cover component. In the grayscale images, black represents zero cover while bright gray or white represents near complete cover (approaching 100\%) of each particular ground cover component. The color composite is a red-green-blue image showing charred NPV (red), green vegetation (green), and uncharred soil (blue) on the Simi fire. The six field sites are marked as white crosses on the southern half of the image strip in the first panel. 


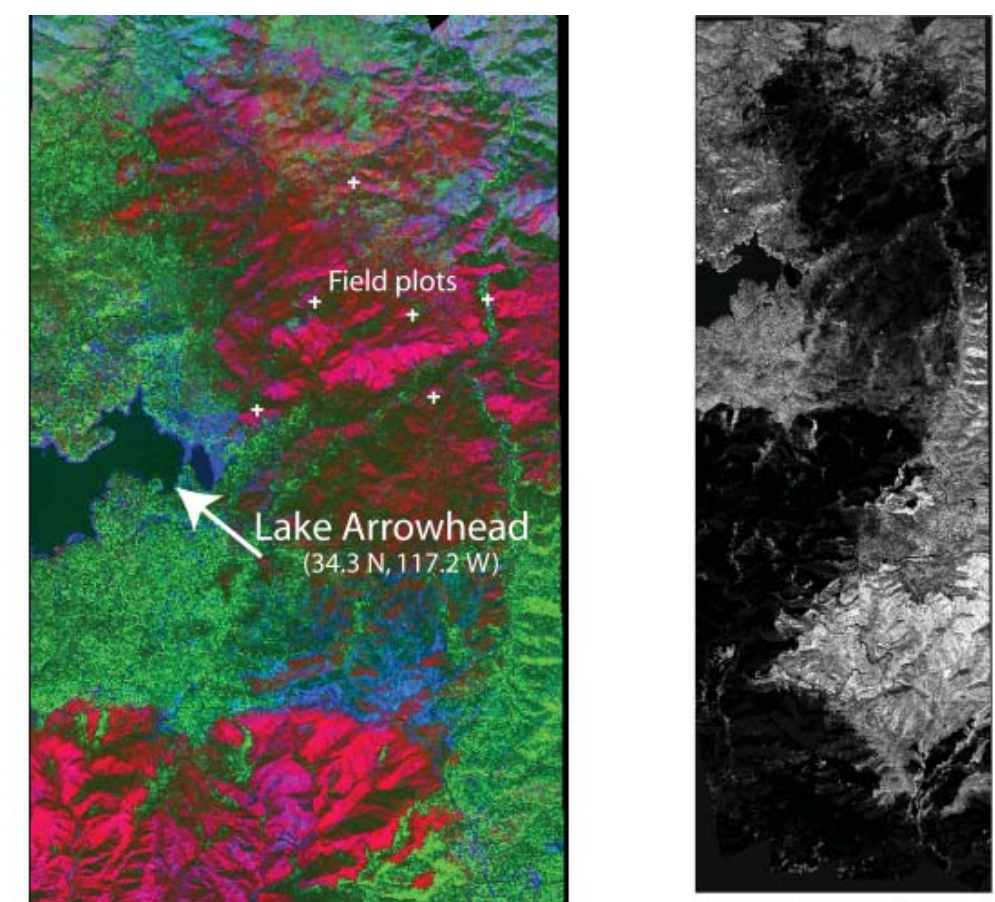

Organic - uncharred

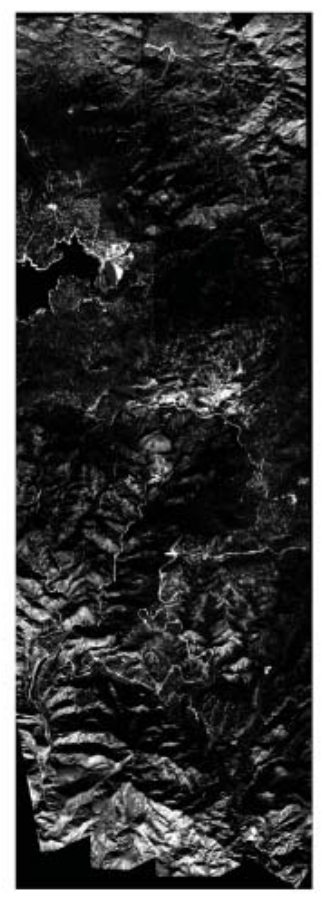

Inorganic - uncharred

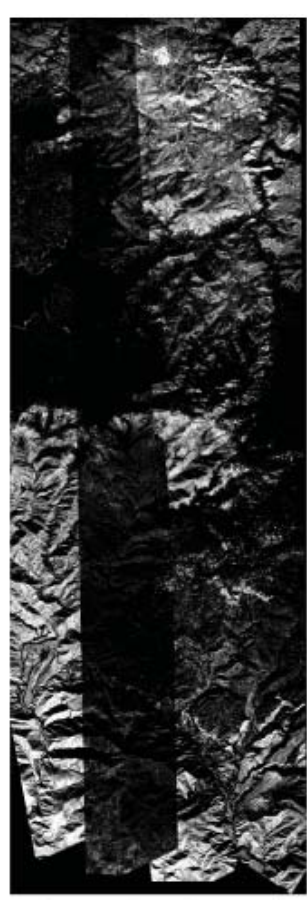

Organic - charred

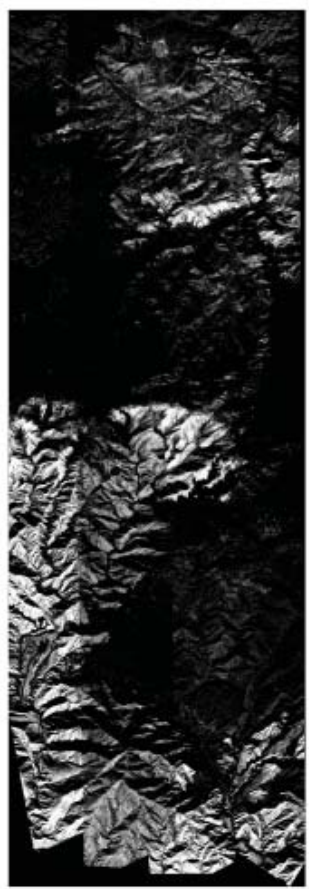

Inorganic - charred

Figure 4. Hyperspectral images of the Old fire highlighting the spectral unmixing results of each major ground cover component. In the grayscale images, black represents zero cover while bright gray or white represents near complete cover (approaching 100\%) of each particular ground cover component. The color composite is a red-green-blue image showing charred NPV (red), green vegetation (green), and uncharred soil (blue) on the Old fire. The six field site locations are marked as white crosses to the north-east of Lake Arrowhead in the first panel. Scale bar is for color composite image only. 
together with a 30-m digital elevation model, were used to generate Input Geometry (IGM) files for georeferencing the imagery. The RTGC reflectance images were georeferenced using the vendor-supplied IGM files. Upon examination, however, the georeferenced images were distorted by up to seven pixels $(\sim 30 \mathrm{~m})$. The IGM solution files were unable to rectify even larger, systematic distortions in the underlying imagery delivered by ESSI. Therefore, we "rubber-sheeted" the IGM output images to a 1-m resolution digital orthophoto mosaic produced in ERDAS Imagine (version 8.7), from digital orthophoto quads downloaded from the California Spatial Information Library (http://archive. casil.ucdavis.edu/casil/remote_sensing/doq). Rubber-sheeting requires a dense, systematic grid of image tie points, which were obtained using an automated, area-based correlation algorithm (Kennedy and Cohen 2003). The program allows the user to specify the size and spacing of the image analysis window, define multiple levels of pixel aggregation, and set scale factors to zoom in and more precisely designate tie points. After manually defining a single image tie point in each flight line to provide the program with a starting reference point, the program generated the rest in a systematic grid across the image. The same parameters were used to produce 810 tie points for the Simi fire image strip, and between 323 and 647 points for the five Old fire image strips, with the number varying as a function of the length of the flight line. The output ASCII files contain the $\mathrm{X}$ and $\mathrm{Y}$ coordinates of the tie points from the input and reference images, which can be imported directly into the ERDAS Imagine georectification utility for rubber-sheeting. Each image strip was resampled to a $4 \mathrm{~m}$ resolution using cubic convolution resampling. The five rectified images at the Old fire were then merged using nearest-neighbor resampling with the mosaic tool in Imagine. Finally, the geolocation accuracy of the rectified Simi fire flight line and Old fire mosaic was verified using approximately a dozen differentially corrected GPS points collected in the field at the middle-of-road intersections near our field sites. All of these GPS points were centered within the width of the road or road intersection (within 2 pixels, or $8 \mathrm{~m}$ ), when displayed over the rectified imagery. Thus, we are confident that the preprocessing steps produced the radiometrically and geometrically rectified hyperspectral imagery needed for this analysis.

Landsat multispectral. Landsat 5 Thematic Mapper (TM) data were obtained for comparing immediate dNBR and RdNBR index values to the hyperspectral image analysis results. For the Simi fire, the pre-fire Landsat scene was collected on 12 September 2002 and the postfire scene was collected on 10 November 2003. For the Old fire, the pre-fire scene was collected on 7 October 2002 and the post-fire scene was collected on 19 November 2003. The images, provided by the Forest Service Remote Sensing Applications Center, were orthorectified, calibrated and converted to top-of-atmosphere reflectance.

\section{Data Analysis}

Ground data. The soil and vegetation data were combined into four categories: uncharred organics (e.g., green vegetation and NPV), charred organics (burned shrub stems, grasses, leaves and needles), uncharred inorganics (rocks and soil), and charred inorganics (rock, soil, and ash) (Table 1). These classes broadly relate to the physical effects of the wildfire on the soil surface, which relate to post-fire processes such as erosion potential. For example, organic ground cover remaining after a wildfire decreases erosion potential by protecting the soil from rainfall and subsequent overland flow. 
Table 1. Mean ground cover characteristics of the field plots on the Simi and Old fires by burn severity class based on dNBR class values - standard error of the mean is in parentheses. Organic ground cover refers to green and non-photosynthetic vegetation, while inorganic refers to soil, rock and ash. The Analysis of Variance (ANOVA) $F$-value statistic is significant at $p<0.05$.

\begin{tabular}{|c|c|c|c|c|c|c|}
\hline \multirow{4}{*}{ Ground cover category } & \multicolumn{4}{|c|}{ Burn severity class } & \multirow{4}{*}{$F$ - value } & \multirow{4}{*}{$p$-value } \\
\hline & Low & Moderate-low & Moderate-high & High & & \\
\hline & \multicolumn{4}{|c|}{ dNBR values } & & \\
\hline & $100-269$ & $270-439$ & $440-659$ & $660-1300$ & & \\
\hline Simi fire plots & $\mathrm{n}=19$ & $\mathrm{n}=22$ & $\mathrm{n}=13$ & $\mathrm{n}=0$ & & \\
\hline Organic-uncharred (\%) & $22(3.2)$ & $8(1.8)$ & $5(2.0)$ & & 13.5 & $<0.0001$ \\
\hline Organic-charred (\%) & $15(2.2)$ & $12(2.3)$ & $7(1.6)$ & & 2.3 & 0.11 \\
\hline Inorganic-uncharred $(\%)$ & $40(3.2)$ & $50(4.6)$ & $43(6.3)$ & & 1.5 & 0.24 \\
\hline Inorganic-charred $(\%)$ & $21(4.4)$ & $28(4.6)$ & $44(6.4)$ & & 4.8 & 0.01 \\
\hline Old fire plots & $\mathrm{n}=3$ & $\mathrm{n}=8$ & $\mathrm{n}=19$ & $\mathrm{n}=24$ & & \\
\hline Organic-uncharred (\%) & $27(5.0)$ & $15(6.0)$ & $5(1.9)$ & $1(0.2)$ & 12.8 & $<0.0001$ \\
\hline Organic-charred (\%) & $4(2.3)$ & $14(4.7)$ & $8(1.1)$ & $6(1.1)$ & 3.3 & 0.03 \\
\hline Inorganic-uncharred (\%) & $38(9.0)$ & $32(7.0)$ & $37(4.5)$ & $16(2.4)$ & 6.6 & 0.0007 \\
\hline Inorganic-charred $(\%)$ & $7(3.1)$ & $38(9.4)$ & $49(4.3)$ & $77(2.4)$ & 24.3 & $<0.0001$ \\
\hline
\end{tabular}

Remotely sensed image data. A linear spectral unmixing algorithm was applied to the pre-processed hyperspectral data to determine pixel fractions of green vegetation (grveg), charred NPV (charveg), and uncharred (soil) and charred (charsoil) inorganic ground cover:

$$
\begin{gathered}
\rho_{\text {pixel }}=\Sigma\left\{\rho_{e} \cdot c_{e}\right\}+\varepsilon=\left\{\begin{array}{l}
\rho_{\text {grveg }} \cdot c_{\text {grveg }}+ \\
\rho_{\text {charveg }} \cdot c_{\text {charveg }}+ \\
\rho_{\text {soil }} \cdot c_{\text {soil }}+ \\
\rho_{\text {charsoil }} \cdot c_{\text {charsoil }}
\end{array}\right\}+\varepsilon \\
\Sigma c_{e}=1.0
\end{gathered}
$$

where $\rho$ and $\mathrm{C}$ are the reflectance and cover fraction of each endmember, respectively, and $\varepsilon$ is an error term. The individual cover fractions sum to unity in Equation 2. The field spectra used as endmembers are shown in Figure 2. The outputs of spectral mixture analysis (SMA) are fractional cover images of the input materials, which are scaled from 0 to 1 . Zero indicates that none of the target material is present in the pixel, while 1 indicates complete cover. In addition to the fractional cover images, a root mean square error (RMSE) image is also produced. This gives an indication of the degree to which the input endmembers matched the extent of the materials on the ground.

Landsat bands 4 (B4) and 7 (B7) were used to calculate the Normalized Burn Ratio (NBR) index (Equation 3), the differenced Normalized Burn Ratio (dNBR) (Equation 4) (Key and Benson 2006) and the Relative dNBR (RdNBR) (Equation 5) (Miller and Thode 2007). The index values were extracted at the plot locations and compared to the ground data.

Endmember fractions were extracted from the unmixed hyperspectral and Landsat images at all subplot locations (i.e., 135 per site). These subplot values were aggregated to the plot scale, i.e., 15 subplots per plot, resulting in 9 plots per site and 54 plots per fire. The spectral fractions and Landsat spectral indices (NBR, dNBR, RdNBR) were compared to the fieldmeasured fractional cover estimates to evaluate how well the image captured the conditions on 
Table 2. Pearson correlation coefficients ( $\mathrm{r}$ ) comparing measured field-plot ground data to hyperspectral spectral mixture analysis (SMA) and multi-spectral indices dNBR and RdNBR. Bold values are significant at $p<0.05$. Organic ground cover refers to green and non-photosynthetic vegetation, while inorganic refers to soil, rock and ash.

\begin{tabular}{lcccccc}
\hline \multirow{2}{*}{ Ground cover category } & \multicolumn{3}{c}{ Simi fire } & \multicolumn{3}{c}{ Old fire } \\
\cline { 2 - 7 } & SMA & dNBR & RdNBR & SMA & dNBR & RdNBR \\
\hline Organic-uncharred & $\mathbf{0 . 6 6}$ & $\mathbf{- 0 . 6 5}$ & $\mathbf{- 0 . 4 8}$ & $\mathbf{0 . 3 6}$ & $\mathbf{- 0 . 7 9}$ & $\mathbf{- 0 . 7 7}$ \\
Organic-charred & 0.52 & -0.27 & -0.11 & $\mathbf{0 . 4 5}$ & -0.17 & -0.27 \\
Inorganic-uncharred & $\mathbf{0 . 3 8}$ & 0.13 & $\mathbf{0 . 3 6}$ & $\mathbf{0 . 4 2}$ & $\mathbf{- 0 . 4 8}$ & -0.23 \\
Inorganic-charred & 0.35 & $\mathbf{0 . 4 7}$ & 0.14 & $\mathbf{0 . 3 2}$ & $\mathbf{0 . 7 2}$ & $\mathbf{0 . 5 5}$ \\
\hline
\end{tabular}

the ground. Analysis of Variance (ANOVA) statistics were calculated (SAS proc GLM) (SAS Institute Inc. 1999) to determine if mean values of each ground cover component were different by burn severity class as determined by dNBR classifications (Key and Benson 2006). Correlations between each endmember and the corresponding ground cover component were assessed using the Pearson correlation statistic at the plot scale (15 aggregated subplots). Scatterplots with ground data as the independent variables and spectral data as the dependent variables were used to further examine the relationship between the ground and spectral data. Linear regressions (SAS proc REG) were calculated from these data, and best-fit lines and coefficients of determination were reported on the scatterplots.

\section{RESULTS}

As dNBR values increased, or as burn severity increased, charred inorganic cover increased and uncharred organic cover decreased on both the Simi and Old fires (Table 1). The sparse vegetation conditions are represented by $30 \%$ to $40 \%$ organic ground cover on the lowest burn severity plots after both fires. On the plots burned at the highest severity, total organic ground cover was $12 \%$ on the Simi fire and 7\% on the Old fire. According to widely applied dNBR classification breaks (Key and Benson 2006), none of our plots on the Simi fire were classified as high burn severity.
The ANOVA analysis showed that the four categories of ground cover (organic-uncharred, organic-charred, inorganic-uncharred, and inorganic-charred) were statistically different across the burn severity classes in most cases. On the Simi fire, the organic-uncharred $(F=$ $13.5, p<0.0001)$ and inorganic-charred $(F=$ $4.8, p=0.01)$ categories had the greatest change from low severity to moderate-high severity (Table 1). On the Old fire, all categories of ground data were significantly different across the four burn severity classes, with inorganiccharred exhibiting the greatest difference $(F=$ $24.3, p<0.0001)$. These results indicate the four-class dNBR breaks were appropriate for investigating the change in post-fire organic and inorganic ground cover on both fires across the range of burn severities.

\section{Correlations Between Ground Data and Remotely Sensed Data}

The spectral fractions from the hyperspectral SMA were significantly correlated to the corresponding ground cover fractions (Table 2 ). The strongest correlation on the Simi fire was between the green vegetation endmember and the field-measured organic-uncharred ground cover $(r=0.66)$. Green vegetation was spectrally distinct in the image and wellmatched to the green vegetation field spectrum used as an endmember. Charred NPV (organiccharred) had the next highest correlation $(r=$ 0.52). On the Simi fire, uncharred $(r=0.38)$ and charred inorganics $(r=0.35)$, had the 
a)

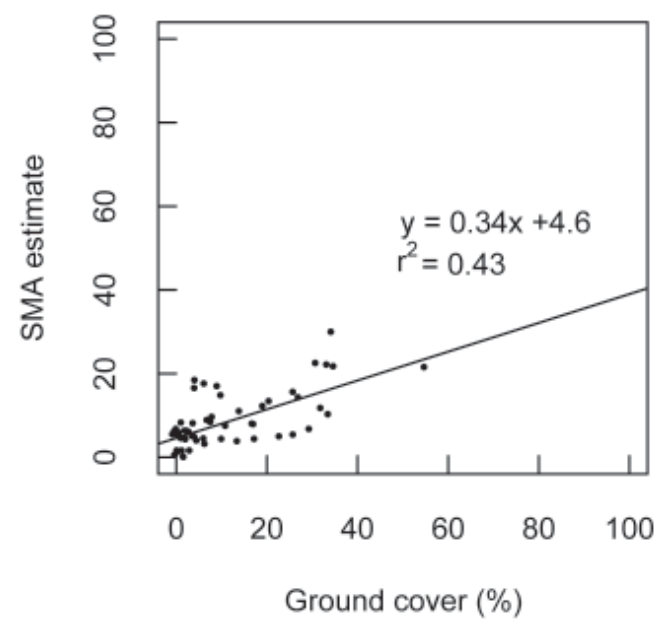

c)

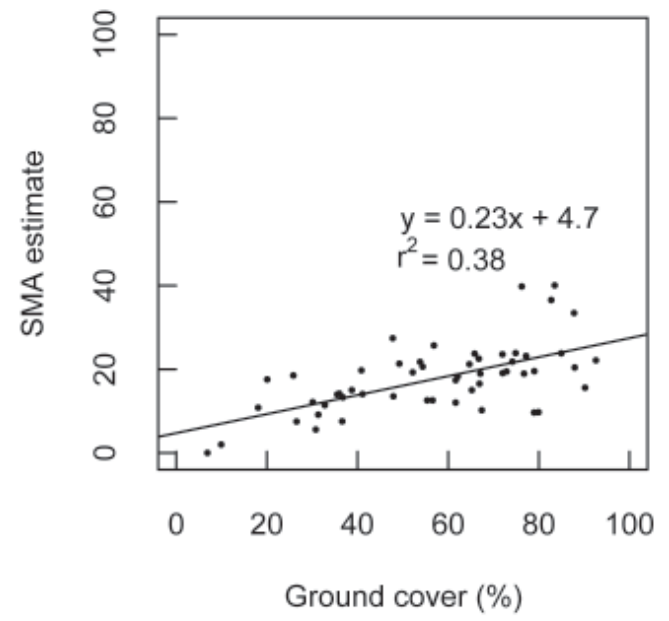

b)

Organic - charred

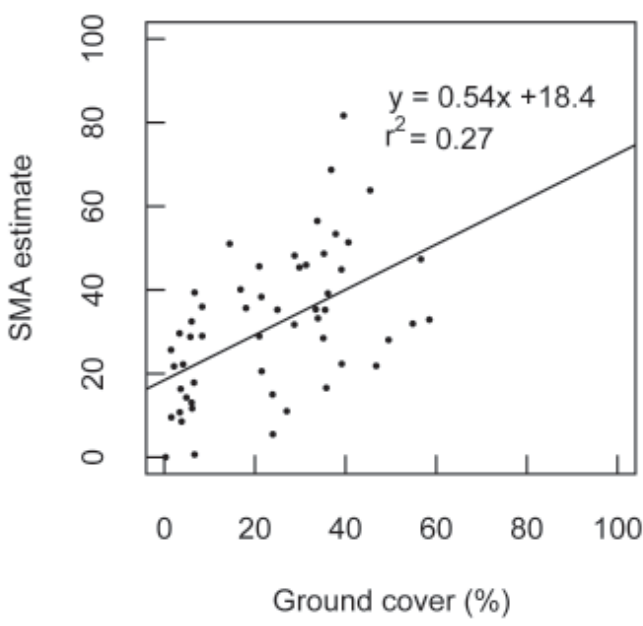

d)

Inorganic - charred

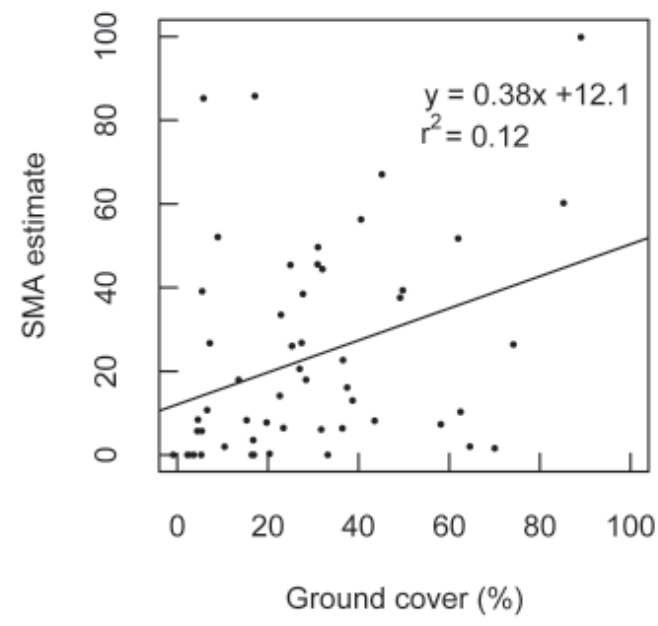

Figure 5. Scatterplots from the Simi fire data of the spectral mixture analysis (SMA) estimates versus the organic and inorganic ground cover components. The number of plots is 54 for all graphs.

lowest correlations between the ground and SMA data. Similar correlations were found with the Old fire data: $r=0.36$ for uncharred organics, $r=0.45$ for charred organics, $r=$ 0.42 for the uncharred inorganics and $r=0.32$ for the charred inorganics (Table 2). These correlations were all statistically significant at $p<0.05$.
Scatterplots of each of these relationships are presented in Figure 5 (Simi fire) and Figure 6 (Old fire). The scatterplots illustrate the relationship between the ground and imaged fractional cover of each major ground cover component. In Figure 5a, it is clear that there was a significant relationship between organiccharred ground cover and the SMA estimate; 
a)

Organic - uncharred

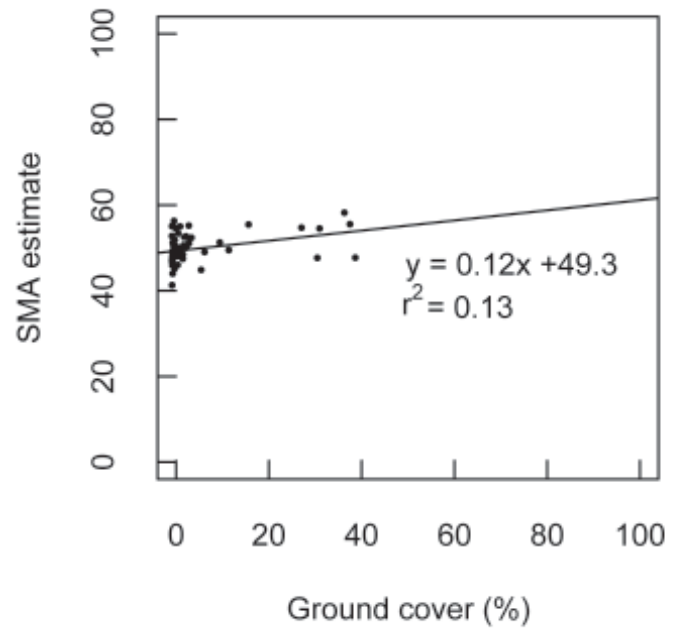

c)

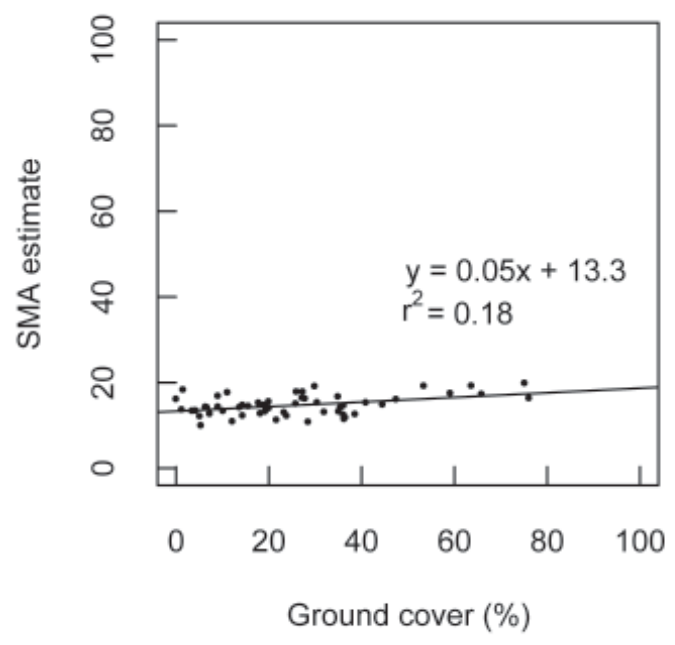

b)

Organic - charred

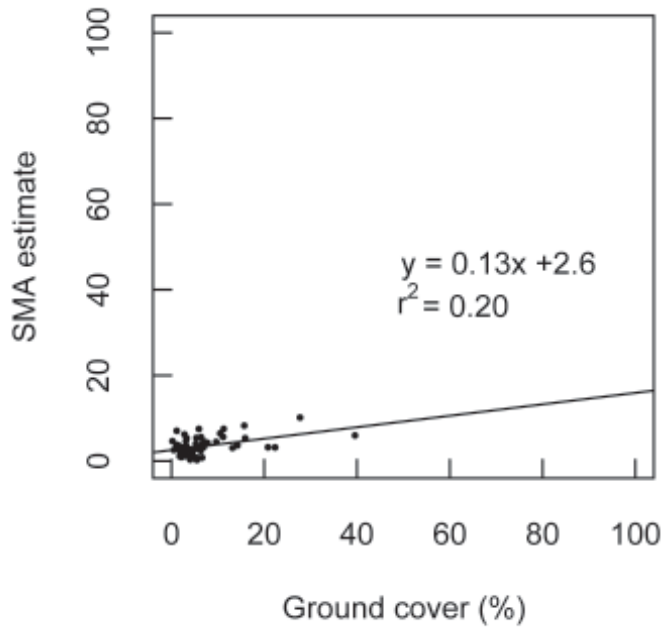

d)

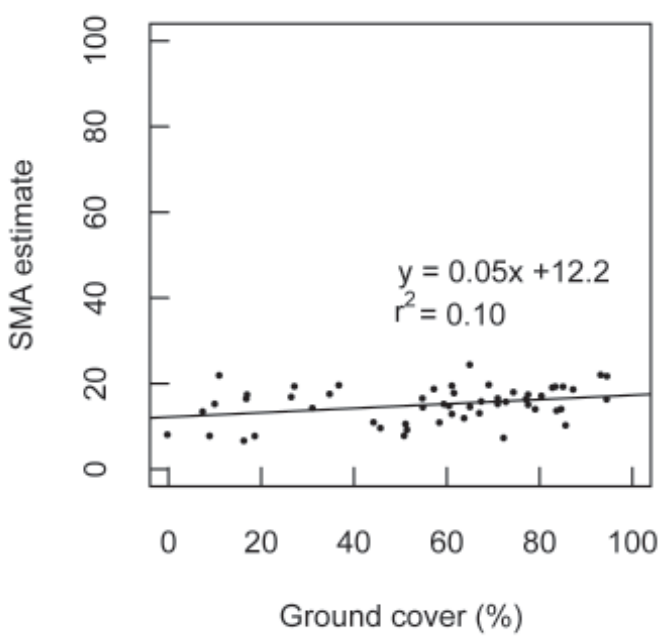

Figure 6. Scatterplots from the Old fire data of the spectral mixture analysis (SMA) estimates versus the organic and inorganic ground cover components. The number of plots is 54 for all graphs.

however, this relationship is not a perfect 1:1. A range of 0 to $55 \%$ organic-uncharred ground cover was measured on the ground; however, $30 \%$ was the most detected on any of the plots in the image. This same trend was found for the other three ground cover classes - the ranges of data measured on the ground are generally higher than the ranges predicted by the SMA results.
On the Old fire, the scatterplots illustrate how little organic cover there was on the ground on our field plots (Figures 6a and 6b). The organic ground data are clustered close to the y-axis, with most of the data points falling below 20\% organic ground cover. More organic-uncharred ground cover was detected in the image than on the ground. This is likely due to the presence of green tree canopies above 
some of the plots and in the nearby area. The inorganic ground cover on the plots (Figures 6c and 6d) shows a different trend as the range of inorganic ground cover on the plots is $0-80 \%$ for uncharred, and 0 to almost $100 \%$ for charred. The maximum amount of inorganic ground cover predicted by the image on any of these plots is $24 \%$. A likely explanation is occluding canopy or shrub vegetation preventing the image from detecting the soil, ash, or rock on these plots.

For comparison, correlations between the ground data and the Landsat-derived dNBR and RdNBR were also calculated (Table 2). As expected, the strongest correlations were found by comparing the satellite imagery to uncharred organics and charred inorganics because of the greater abundance of these cover types in unburned and low burn severity areas and high burn severity areas, respectively. Lower overall correlations were found between the charred organic and uncharred inorganic classes and the dNBR and RdNBR values (Table 2). Charred organics and uncharred inorganics found in mixed quantities across the spectrum of burn severity do not by themselves define a burn severity classification, or the degree of change from pre-fire conditions. Therefore, we did not expect that these cover types would be highly correlated with indices that indicate degree of change from pre-fire conditions, such as a burn severity class.

\section{Spectral Mixture Analysis Images}

The RMSE was 0.04 or less across both fire images, indicating that the endmembers used in the spectral unmixing corresponded well to the ground cover types in the images. The SMA results for the Simi fire for each of the major ground cover components are shown as grayscale images (scale $0-1$ where 1 is $100 \%$ cover) (Figure 3 ). This subset is little uncharred vegetation (green or senesced NPV) within the image. Conversely, charred NPV (organic-charred) is extensive throughout the image. Similarly, there is little uncharred soil (inorganic-uncharred) shown in the image while charred soil, ash, and rock (inorganiccharred) is extensive. In the color composite image, charred NPV (organic-charred) is shown as red, green vegetation (organic-uncharred) as green, and uncharred soil (inorganic-uncharred) as blue. These images are a relatively small subset $(\sim 15 \%)$ of the Simi fire, however the full range of burn severity conditions are included, as well as small portions extending outside the burn area at the north and south ends of the image. Charred NPV is present across the entire image, much of it mixed with soil, and shows as a purple or magenta color. The only green vegetation is located in discrete areas, mostly in valley bottoms. Large patches of bright blue are rocky outcrops and the darkest areas are topographic shadows.

The Old fire burned primarily in interior woodlands with a mix of chaparral. The result was a much greater proportion of burned and unburned vegetation (organic-charred and organic-uncharred) remaining after the Old fire than after the Simi fire due to the higher proportion of pre-fire vegetation (Figure 4). The grayscale images show extensive charred and uncharred vegetation throughout the area. The highlighted areas of organic-charred and organic-uncharred nearly completely cover the image area, indicating little soil or rock being detected in the images. Inorganics, both uncharred and charred, are mostly found within the burned area, because tree canopy occludes the soil in the unburned areas. The pattern of inorganic-charred is close to a mirror image of organic-uncharred. It is relatively easy to distinguish burned and unburned areas in these images. In the color composite, charred NPV (organic-charred) is shown as red, green vegetation (organic-uncharred) as green, and uncharred soil (inorganic-uncharred) as blue. The fire perimeter is identifiable on the image where the red color within the burned area turns sharply to a green color outside of the burned area. 


\section{DISCUSSION}

The extent to which the ground surface was burned and the amount of remaining organic ground cover are good indicators of the effects of the fire on the soil surface. Figures 3 and 4 are essentially post-fire ground cover maps, highlighting exposed mineral soil and the charred components. An assessment of the fire effects on the soil surface gives a reasonable indication of the potential for hydrologic response. These ground cover maps, combined with topographic data could be helpful immediately after a fire when BAER teams must determine which areas to treat to mitigate erosion.

None of the field plots on the Simi fire were classified as high burn severity using published dNBR classification breaks (Key and Benson 2006). dNBR values are normally classified into four categories: unburned (values $<100$ ), low burn severity $(100-269)$, moderate burn severity (270 - 659), and high burn severity $(660-1,300)$. There are two sub-classes of moderate burn severity that are less commonly used: moderate-low $(270-439)$, and moderatehigh $(440-659)$. These classes were used because none of the field plots on the Simi fire had dNBR values above 659 , even though many of the moderate-high plots had characteristics of higher burn severity (Table 1). There was an average of $37 \%$ organic ground cover on the plots burned at low severity and an average of $12 \%$ organic ground cover on the plots burned at moderate-high severity. On the moderatehigh plots, this leaves nearly $90 \%$ of the soil exposed for potential erosion by wind or water. A large percentage of the inorganic component is uncharred on all plots, regardless of burn severity class (Table 1). For post-fire soil to appear charred, significant combustion and surface soil heating must occur. In much of the Simi fire area, patchy pre-fire vegetation resulted in spotty areas of intense fire and interspace areas of rapid fire spread.
The steep topography of the Simi fire area can be seen in Figure 3 from the shading on the north sides of ridges. The Old fire burned in similarly steep terrain, which is not as obvious from the images. The combination of steep terrain, burned soils, and lack of vegetative cover increases the potential for soil erosion. Our results suggest that a significant amount of vegetative cover was removed by the fire in some areas and that the soil there likely experienced extended heating, resulting in fire-induced water repellent soils and reduced infiltration capacity. We measured a relative infiltration rate on all sites using a mini-disk infiltrometer (Decagon Devices Inc., 2003) and found that most of the soils had a very low infiltration capacity $(<1 \mathrm{ml}$ $\left.\min ^{-1}\right)$. For reference, a similarly unburned soil will generally have an infiltration rate of $>8 \mathrm{ml}$ $\min ^{-1}$ (Lewis et al. 2007).

Much of the Simi fire area was covered by a combination of charred and uncharred NPV after the fire. These components were difficult to separate both spectrally and in the field. The spectral endmembers appeared to be a mix of charred shrub stem reflectance and charred soil background reflectance (Figure 2). Charred soil and charred NPV endmembers were similar with charred NPV (organic-charred) having a stronger relationship between the image and ground data than charred soil (inorganic-charred) (Table 2). The stronger correlation between uncharred organic field component and the SMA results indicates that green vegetation was easy to identify in the image and the spectral endmember was a good match for the image data. One issue with green vegetation remaining in a post-fire scene is its occlusion of the ground below (Hudak et al. 2007). In an area with extensive remaining canopy vegetation, such as on the Old fire, the canopy will block the view of the soil surface, resulting in potentially poor correlations between ground cover data and image data. This was an issue with images from the Old fire because of the dominance of mixed-confer 
vegetation, rather than the sparse chaparral vegetation generally found in the Simi fire area. These results are evident on the scatterplots of ground cover versus the SMA estimates. On the plots of the Simi fire data (Figure 5), the linear regressions show higher slopes than the plots of Old fire data (Figure 6). This indicates the SMA estimates of ground cover were higher (although still lower overall than the ground cover measures) for the Simi fire data than for the Old fire data. This closer estimate is likely the result of less occlusion of the ground from remaining canopy vegetation (canopy cover $>1 \mathrm{~m}$ high averaged $0-1 \%$ on four of six field sites). On the Old fire, SMA estimates were low for all categories except organic uncharred vegetation. Canopy cover ranged from $1 \%$ to $32 \%$ on the Old fire field plots, suggesting the organic uncharred category was reflective of remaining canopy vegetation.

The sparse ground vegetation on our field plots across the range of burn severity on the Simi fire and the mixed vegetation on the Old fire justified the need to explore alternate methodologies other than dNBR for postfire mapping. Because of the lack of pre-fire vegetation or litter to burn, dNBR results were likely skewed by the complete absence of vegetation on some sites regardless of the actual effects of the fire at that site. To fairly assess the RdNBR relative change index, it must be acknowledged that it is not designed to identify specific ground cover types (Miller and Thode 2007). The NBR is derived from a near-infrared band (B4) and a shortwave infrared band (B7), which are highly sensitive to water content of vegetation - changes in live, green vegetation will therefore have the greatest impact on the index values. The dNBR and RdNBR assign a value to the absolute change (dNBR), or relative change (RdNBR), from a pre-fire to a post-fire condition. Areas with abundant green or nonphotosynthetic (non-charred) vegetation after a fire are generally unchanged and classified as low burn severity. Areas that have little or no vegetation remaining and have abundant charred soil and ash have generally undergone a great change and are classified as high burn severity. Therefore, it is reasonable that these cover types had the strongest correlations with the dNBR and RdNBR values (Table 2).

The dNBR and RdNBR values were most strongly correlated to the organic-uncharred and inorganic-charred categories of ground cover, with few significant correlations to the organic-charred and inorganic-uncharred categories (Table 2). These results indicate that the dNBR and RdNBR are good at identifying areas that were relatively unchanged (low burn severity) and significantly changed (high burn severity) after a fire. These areas are often relatively homogenous, with extensive green tree canopies or conversely, a "moonscape" with widespread charred soil, ash, and black charred vegetation. It is the moderately burned areas with mixed characteristics in the middle of the burn severity spectrum that are more difficult to identify using remote sensing. Moderately burned areas are often a mix of burn severity conditions and characteristics. The effects of the fire on the ground do not always match the effects in the above-ground vegetation, which is most often reflected in satellite imagery. The correlations between the hyperspectral SMA results and all four organic and inorganic ground cover categories were statistically significant (Table 2), indicating a better ability to discern moderate burn severity effects when compared to the dNBR or RdNBR. It is important to be able to map moderate fire effects such as uncharred inorganics and charred organics because exposed mineral soil is prone to erosion, even if it is unburned, and organic cover on the soil surface, even if it has been burned, provides soil protection from wind and water. An additional benefit to using airborne hyperspectral imagery over satellite imagery is the scale at which postfire maps can be produced. The hyperspectral imagery used in this study had 4.2-m pixels 
on the ground compared to $30-\mathrm{m}$ pixels in the satellite imagery. The ability to detect earthsurface components at a finer scale improves the accuracy at which post-fire components and conditions can be mapped.

All correlations between the ground and remotely sensed data would likely be improved if the ground data and the hyperspectral image data were collected simultaneously. Because of logistical and safety concerns and the presence of smoke, ground data and image data are not easily acquired immediately after a fire, or even at the same time. There was a one-month delay after the ground data were collected before the hyperspectral images were acquired and during this time, the Simi fire BAER team observed that post-fire wind and rain events re-distributed white ash, characteristic of complete vegetation combustion (CDF 2003). Hudak et al. (2004) also found weak correlations between similar field and multispectral satellite data across multiple fires that had burned in a variety of forest vegetation types, and speculated that the time between fire and the collection of field data was a factor. Hudak et al. (2007) quantitatively determined that time lags contributed to weaker correlations between image indices and field fire effects across the Simi and Old fires along with four other wildfires in Montana and two in Alaska. The inclusion of shaded vegetation and a shaded soil component in the spectral unmixing may have improved correlations due to the steep topography in many places on the Simi fire. We experimented with a photometric shade endmember (zero reflectance across all wavebands), but it did not improve correlations between the spectral and field fractional covers; thus, it was not included in the final results. It would have been difficult to derive a highquality shaded soil or vegetation endmembersuch an endmember would had to have been derived from the image, and we were hesitant to add a mixed image spectrum to the 'pure' field spectra used in the rest of the analysis.

\section{CONCLUSIONS}

The endmembers used in the spectral unmixing processes for the Simi and Old fires were representative of the burned area. There were significant correlations between spectral abundance in the image and fractional cover measured on the ground for each of the endmembers used in the spectral unmixing. The Simi and Old fires presented unique situations for exploring alternative methods for post-fire mapping. The chaparral vegetation on both fires was sparse both pre-and post-fire, and the Old fire also burned in woodland vegetation areas, creating conditions shown to be potentially incompatible with the relative change indices dNBR and RdNBR. The spectral unmixing results from the hyperspectral imagery were significantly correlated to all classes of charred and uncharred organics and inorganics. The dNBR was the best indicator of charred inorganics and uncharred organics, while RdNBR had several significant correlations with the ground data, yet did not consistently correlate well with any specific ground cover types. Overall, the results of the spectral mixture analysis were slightly better than the dNBR and RdNBR at predicting quantitative ground cover categories rather than burn severity classes.

While hyperspectral data are currently costly to obtain and time consuming to process, they will be useful in future post-fire assessments as hyperspectral image acquisition and processing becomes more timely and affordable. The field spectra used as endmembers in the Simi and Old fire analyses will be useful on future fires in areas with similar vegetation types. The ability to quantify the exposed soil and remaining vegetation provides a useful assessment of the fire's effects on the ground surface. In turn, the condition of the soil and the potential for postfire hydrologic response can be more accurately assessed. 


\section{ACKNOWLEDGEMENTS}

We would like to thank the US Department of the Interior and Department of Agriculture Forest Service, Joint Fire Science Program (JFSP 03-2-1-02) for funding this project. This research was supported in part by funds provided by the US Department of Agriculture, Forest Service, Rocky Mountain Research Station, to the University of Idaho (03-JV-11222065-279). Troy Hensiek, Jared Yost, Kate Schneider (RMRS) and Carter Stone (University of Idaho) assisted with field data collection, and Jacob Young and Curtis Kvamme (RMRS) with data entry. We sincerely appreciate the support of local natural resources managers and Incident Management Teams in each location.

\section{LITERATURE CITED}

Adams, J.B., M.O. Smith, and P.E. Johnson. 1985. Spectral mixture modeling: a new analysis of rock and soil types at the Viking Lander 1 site. Journal of Geophysical Research 91(B8):80988112.

AIG (Analytical Imaging and Geophysics, LLC). 2002. ACORN 5.0 User's Guide. Boulder, Colorado.

Barro, S.C., and S.G. Conard. 1991. Fire effects on California chaparral systems: an overview. Environment International 17(2-3):135-149.

Beyers, J.L. 2004. Postfire seeding for erosion control: effectiveness and impacts on native plant communities. Conservation Biology 18:947-956.

Cannon, S.H., J.E. Gartner, M.G. Rupert, and J.A. Michael. 2003. Emergency assessment of debris-flow hazards from basins burned by the Piru, Simi, and Verdale fires of 2003, southern California. U. S. Geological Survey Open-File Report 03-481.

California Department of Forestry and Fire Protection (CDF). 2003. Emergency watershed protection assessment, Simi and Verdale incidents. <http://frap.cdf.ca.gov/socal03/reports/ SimiVerdaleFinalReport.pdf $>$. Accessed 30 May 2006.

Clark, J., A. Parsons, T. Zajkowski, and K. Lannom. 2003. Remote sensing imagery support for burned area emergency response teams on 2003 southern California wildfires. USDA Forest Service Report RSAC-2003-RPT1.

Clark, R.N., G.A. Swayze, K.E. Livo, R.F. Kokaly, T.V. King, J.B. Dalton, J.S. Vance, B.W. Rockwell, T. Hoefen, and R.R. McDougal. 2002. Surface reflectance calibration of terrestrial imaging spectroscopy data: a tutorial using AVIRIS. Proceedings of the $10^{\text {th }} \mathrm{JPL}$ Airborne Sciences Workshop. R.O. Green, editor. Jet Propulsion Laboratory, Pasadena, California. $<$ http://speclab.cr.usgs.gov/PAPERS.calibration.tutorial $>$. Accessed 23 August 2007.

DeBano, L.F. 2000. The role of fire and soil heating on water repellency in wildland environments: a review. Journal of Hydrology 231-232:195-206.

Decagon Devices Inc. 2003. Decagon Biophysical Instruments: Mini-disk infiltrometers. <http:// www.decagon.com/instruments/infilt.html>. Accessed 3 April 2007.

Hanes, T.L. 1977. California chaparral. Pages 417-469 in: M.G. Barbour, and J. Major, editors. Terrestrial Vegetation of California. John Wiley and Sons, New York, New York, USA.

Hubbert, K.R. 2005. Treatment effectiveness monitoring for southern California wildfires: 2003 to 2004. The Cedar, Grand Prix/Old, Piru, and Padua fires. <http://www.fs.fed.us/psw/ publications/4403/BAEREffectivenessMonitoringSoCA.pdf $>$ Accessed 22 October 2007. 
Hubbert, K.R., H.K. Preisler, P.M. Wohlgemuth, R.C. Graham, and M.G. Narog. 2006. Prescribed burning effects on soil physical properties and soil water repellency in a steep chaparral watershed, southern California, USA. Geoderma 130:284-298.

Hudak, A.T., P. Morgan, M.J. Bobbitt, A.M.S. Smith, S.A. Lewis, L.B. Lentile, P.R. Robichaud, J.T. Clark, and R.A. McKinley. 2007. The relationship of multispectral satellite imagery to immediate fire effects. Fire Ecology 3(1):64-90.

Hudak, A.T., P.R. Robichaud, J.B. Evans, J. Clark, K. Lannom, P. Morgan, and C. Stone. 2004. Field validation of Burned Area Reflectance Classification (BARC) products for post-fire assessment. In: J. Greer, editor. Remote Sensing for Field Users. Proceedings of the Tenth Forest Service Remote Sensing Applications Conference. USDA Forest Service, Salt Lake City, Utah, 5-9 April 2004.

Ice, G.G., D.G. Neary, and P.W. Adams. 2004. Effects of wildfire on soils and watershed processes. Journal of Forestry 102(6):16-20.

Jia, G.J., I.C. Burke, A.F.H. Goetz, M.R. Kaufmann, and B.C. Kindel. 2006. Assessing spatial patterns of forest fuel using AVIRIS data. Remote Sensing of Environment 102:318-327.

Keeley, J.E. 2000. Chaparral. Pages 203-205 in: M.G. Barbour and W.D. Billings, editors. North American Terrestrial Vegetation. Second edition. Cambridge University Press, United Kingdom.

Keeley, J.E. 2006. Evolution of plant adaptations. Pages 350-390 in: N.G. Sugihari, J.W. van Wagtendonk, J. Fites-Kaufman, K.E. Shaffer, and A.E. Thode, editors. Fire Ecology of California's Ecosystems. University of California Press, Berkeley, California, USA.

Keeley, J.E., and C.J. Fotheringham. 2001. History and management of crown-fire ecosystems: a summary and response. Conservation Biology 15:1561-1567.

Kennedy, R.E., and W.B. Cohen. 2003. Automated designation of tie-points for image-to-image coregistration. International Journal of Remote Sensing 24:3467-3490.

Key, C.H., and N.C. Benson. 2006. Landscape assessment: sampling and analysis methods. Pages 219-273 in: D.C Lutes, editor. FIREMON: Fire Effects Monitoring and Inventory System. USDA Forest Service General Technical Report RMRS-GTR-164-CD.

Kokaly, R.F., B.W. Rockwell, S.L. Haire, and T.V.V. King. 2007. Characterization of post-fire surface cover, soils, and burn severity at the Cerro Grande fire, New Mexico, using hyperspectral and multispectral remote sensing. Remote Sensing of Environment 106:305-325.

Lentile, L.B., Z.A. Holden, A.M.S. Smith, M.J. Falkowski, A.T. Hudak, P. Morgan, S.A. Lewis, P.E. Gessler, and N.C. Benson. 2006. Remote sensing techniques to assess active fire characteristics and post-fire effects. International Journal of Wildland Fire 15:319-345.

Lewis, S.A., P.R. Robichaud, B.E. Frazier, J.Q. Wu, and D.Y.M. Laes. In press. Using hyperspectral imagery to predict post-wildfire soil water repellency. Geomorphology.

Lewis, S.A., J.Q. Wu, and P.R. Robichaud. 2006. Assessing burn severity and comparing soil water repellency, Hayman fire, Colorado. Hydrological Processes 20:1-16.

Lutes, D.C., R.E. Keane, J.F. Caratti, C.H. Key, N.C. Benson, S. Sutherland, and L.J. Gangi. 2006. In: D.C Lutes, editor. FIREMON: Fire effects monitoring and inventory system. USDA Forest Service General Technical Report RMRS-GTR-164-CD.

McCullough, D.G., R.A. Werner, and D. Neumann. 1998. Fire and insects in northern and boreal forest ecosystems of North America. Annual Review of Entomology 43:107-127.

Miller, J.D., and A.E. Thode. 2007. Quanifying burn severity in a heterogeneous landscape with a relativized version of the delta Normalized Burn Ratio (dNBR). Remote Sensing of Environment 109:66-80. 
Miller, J. D., and S.R. Yool. 2002. Mapping forest post-fire canopy consumption in several overstory types using Landsat TM and ETM data. Remote Sensing of Environment 82:481-496.

Ravi, S., P. D’Odorico, B. Herbert, T. Zobeck, and T.M. Over. 2006. Enhancement of wind erosion by fire-induced water repellency. Water Resources Research 42(11):1-9.

Roberts, D.A., M.O. Smith, and J.B. Adams. 1993. Green vegetation, nonphotosynthetic vegetation and soils in AVIRIS data. Remote Sensing of Environment 44:255-269.

Robichaud, P.R. 2000. Fire effects on infiltration rates after prescribed fire in northern Rocky Mountain forests, USA. Journal of Hydrology 231-232:220-229.

Robichaud, P.R., S.A. Lewis, D.Y.M. Laes, A.T. Hudak, R.F. Kokaly, and J.A. Zamudio. 2007. Postfire soil burn severity mapping with hyperspectral image unmixing. Remote Sensing of Environment 108(4):467-480.

Robichaud, P.R., J.L. Beyers, and D.G. Neary. 2000. Evaluating the effectiveness of postfire rehabilitation treatments. USDA Forest Service General Technical Report RMRS-GTR-63.

SAS Institute Inc. 1999. SAS/STAT User's Guide, Volume 1, Version 8.2. Statistical Analysis Systems (SAS) Institute Inc., Cary, North Carolina.

Savage, M. 1997. The role of anthropogenic influences in a mixed-conifer forest mortality episode. Journal of Vegetation Science 8(1):95-104.

Smith, M.O., S.L. Ustin, J.B. Adams, and A.R. Gillespie. 1990. Vegetation in deserts: I. a regional measure of abundance from multi-spectral images. Remote Sensing of Environment 31:1-26.

Theseira, M.A., G. Thomas, J.C. Taylor, F. Gemmell, and J. Varjo. 2003. Sensitivity of mixture modeling to end-member selection. International Journal of Remote Sensing 24(7):15591575.

US Department of Agriculture (USDA). 2006. Soil survey for Ventura area, California. <http:// websoilsurvey.nrcs.usda.gov/app/WebSoilSurvey.aspx>. Accessed 13 March 2007. 